\title{
Arctic Observing Summit (AOS) 2018 Statement and Call to Action
}

\author{
by AOS Executive Committee Members
}

\section{FOREWORD}

$\mathrm{T}$ The Arctic Observing Summit (AOS) is an international conference that aims to provide community-driven, science-based guidance for the design, implementation, coordination, and operation of a sustained (decades-long) international network of Arctic observing systems. The AOS provides a platform for addressing urgent and broadly recognized needs of Arctic observing across all components of the Arctic system, including the human component. The AOS fosters communication and international collaboration and coordination of long-term observations to improve our understanding of system-scale Arctic change and responses to it. The AOS is an international forum that aims to optimize resource allocation, minimize information gaps, and avoid duplication by coordinating efforts and exchanging information among researchers, agencies, northern peoples, non-governmental organizations, the private sector, and others involved or interested in longterm observing activities.

The 2018 AOS was the fourth Summit, following those held in Vancouver, Canada, in 2013, Helsinki, Finland in 2014, and Fairbanks, USA, in 2016. Summits are structured thematically, building iteratively on previous outcomes and recommendations. In 2018, delegates focused on the business case for a pan-Arctic observing system. The following statement summarizes the main conclusions, recommendations, and call to action from the Arctic Observing Summit 2018 held in Davos, Switzerland, on 24-26 June 2018. The Summit Statement is based on the summaries of the working group deliberations and was reviewed during the final plenary session of the conference. In addition to the Summit Statement below, background documents, presentations, and materials from previous events can be found at www.arcticobservingsummit.org.

\section{STATEMENT}

We are living in the Anthropocene - a new era with human activities altering the planet in ways never experienced before. One of the fastest changing regions on the earth is the Arctic where impacts of major transformations are felt both earlier and more strongly than elsewhere in the world. As an integral part of the Earth system, the Arctic is shaped by global processes, and in turn, Arctic processes influence living conditions of hundreds of millions of people at lower latitudes.

Through the efforts of governments, international organizations, Indigenous Peoples, academicians, and many others, there is real progress in observing a rapidly changing Arctic. Numerous examples illustrate how insight from such observations enables, informs, and enhances decision making at local to pan-Arctic scales. More, however, must be done, particularly with respect to the range, distribution, and continuity of Arctic observing.

The Arctic has supported the lives of Arctic Indigenous Peoples for millennia and provides their economic security, as well as their cultural and spiritual well-being. Arctic Indigenous Peoples have acquired a dynamic knowledge system, allowing for a broader understanding across biological, physical, social, and spiritual domains. To fully benefit decision making at all scales, this knowledge and Indigenous societal priorities need to play a central role in the development of future Arctic Observing Systems. At the same time, developing capacities and enterprises to allow Indigenous Peoples and Arctic communities to fully engage in observing efforts requires urgent attention.

We have confidence, based on examples where sustained observations have led to positive outcomes, that expanding observing activities will reduce vulnerability and build resilience of Arctic societies, environments, and infrastructure. Not doing so increases the risk of greater impacts and associated costs. Importantly, optimization of existing observational capabilities and addition of new components will require enhanced coordination at an international level.

\section{RECOMMENDATIONS AND CALL TO ACTION}

Since the AOS-2016 (Fairbanks, Alaska, USA), analytical advances, in a series of efforts that emerged from the first Arctic Science Ministerial (ASM 1), have provided quantitative and qualitative valuation methods to support informed decisions drawing on the societal benefits of sustained observing systems and accessible data. Case studies for selected Arctic challenges have shown positive return on investment, motivating our call for action to coordinate and extend sustained observations.

Compared to other, more populated parts of the globe, the Arctic must rely heavily on research projects, rather than operational infrastructures and initiatives, in order to carry out observations. There is an urgent need to progressively shift key observing system componentsincluding community-based observations-from short-term research funding to sustained, operational infrastructure support. The operational infrastructure of the Arctic Observing System must target key variables that capture the Arctic system's main features. The set of key variables must be augmented through observation of the broader set of variables needed to address topical problems through research projects. Such a system also serves a 
critical function as information infrastructure in support of global services derived from the Arctic system.

A properly resourced, comprehensive effort is needed to identify strengths and gaps in the current set of systems, sensors, networks, and surveys used to observe the Arctic. A knowledge map connecting these observations to societal benefits can then guide new observations, data management needs, and development of products and services, leading to a much-needed roadmap for Arctic system observing. Support for an international and local team of experts to complete these tasks under the auspices of Sustaining Arctic Observing Networks (SAON) will greatly increase the benefits derived from Arctic observing activities and is deemed critical for successful deployment and sustained operation of an Arctic Observing System.

1. It is essential that observing and data systems, at different spatial and temporal scales, emerge from co-design, co-production, and co-management processes with relevant stakeholders and rights-holders who embrace free, ethical, and open data sharing and adhere to the "FAIR" (Findable, Accessible, Interoperable, Reusable) data principles.
2. To build an Arctic Observing System that is comprehensive, coordinated, and sustainable, and which fills current observational gaps, all existing assets and activities, including Indigenous knowledge, must be leveraged to the greatest extent. Such a system needs to span the full range of spatial and temporal observation scales. This is achievable by combining multiple observational methods and technologies, including Indigenous knowledge, community-based monitoring, and citizen science, and by linking all relevant data systems.

This Statement builds on deliberations at the international biennial Arctic Observing Summit (AOS). AOS is a task of SAON under the auspices of the Arctic Council and the International Arctic Science Committee (IASC). At AOS-2018 (Davos, Switzerland), participants from 26 countries focused on the "Business Case for a Pan-Arctic Observing System." Demonstrating the value of Arctic observations, linked to relevant societal benefit areas, showed how long-term observing systems support decision making from local to global scales. 